\title{
Labor and Delivery Complication
}

National Cancer Institute

\section{Source}

National Cancer Institute. Labor and Delivery Complication. NCI Thesaurus. Code

C87091.

The occurrence of a pregnancy complication during childbirth, which includes both labor (the process of childbirth) and delivery (the birth itself). 